\title{
Introduction to Intentional Forgetting in Organizations and Information Systems Minitrack
}

\begin{abstract}
Knowledge creation and organizational learning relies on the cognitive capacity of an organization, its members and its information systems. Processing new signals from the environment and generating new meaningful information is one key factor for successful management. However, with the increasing amount of information within and outside the organization, this process can slow down or lead to contradicting results. Organizational learning is distorted. Forgetting unused, obsolete and contradicting information is therefore the key of an efficient learning process as it frees up this capacity. This Mini-Track addresses the forgetting paradigm in organizations and information systems.
\end{abstract}

\section{Introduction}

The organizations knowledge and learning capabilities are a main source of competitive advantage. As organizations learn, their processes, structures and information systems adapt to the changing requirements in the environment. However, the high amount of available and stored knowledge can also lead to difficulties in interpreting information and might impede the evaluation of alternative ways to reach strategic goals [1]. This will also result in uncertainty about which goals can be achieved under consideration of all knowledge [2] or to problems with establishing connections and causalities [3] and patterns among the noise of all of the available knowledge.

As knowledge acquisition and sharing as well as learning have been acknowledged and valued as important processes on individual, team and organizational level $[4,5,6,7]$ research also has to focus on forgetting as another perspective of learning. Forgetting is therefore not a malfunction but an essential adaptive function of knowledge based systems. In order to actively use functions, forgetting has to be managed, it has to occur intentionally and not accidentally.

The research stream of intentional forgetting addresses this problem on the individual level. This principle was first researched in the field of psychology $[8,9,10,11]$ but recent works show its potential in the organizational $[12,13,14,15,16]$ and technical context [2] for adaptive and agile systems.

This mini-track explores various ways in which forgetting can be researched.

\section{Paper Overview}

Three papers will be presented in this mini-track, they give an insight in different areas of research.

Haase and Schueffler will present an experimental approach on measuring forgetting in production routines. This interdisciplinary contribution uses a real work routine and modifies it so different factors influencing forgetting can be assessed in a laboratory experiment. The experiment combines individual forgetting as well as effects on the group level as participants interact with one another in the production process. The laboratory consists of a hybrid factory simulation, providing immersion as well as controllability in the experiment. The authors furthermore elaborate on the experimental conditions, which they are testing.

The second contribution by Timm et al is also applying an interdisciplinary approach. They investigate the effects of role configurations in logistics by using psychological experiments along with a multiagent simulation. The task in this combined humancomputer experiment is to coordinate the extinction of a forest fire. Different knowledge distributions are tested from a specialist to a generalist approach. By shifting the knowledge distribution within the organization (meaning some actions are forgotten), an optimal configuration of the roles can be determined.

The third contribution by Thim, Gronau and Kluge focusses on the management aspects of forgetting by researching the effects of controlled changes in the workplace during process transformations. Drawing on the psychological concept of retrieval cues, the paper classifies different cue types and maps them to elements in business processes. By actively modifying certain elements at the workplace, e.g. the persons working in teams, information material or user interfaces, forgetting can be aided smoothing the relearning of new processes and process steps during change. The proposed changes are validated experimentally. 


\section{References}

[1] R. Lipshitz and O. Strauss, "Coping with uncertainty: A naturalistic decision-making analysis," Organizational Behavior and Human Decision Processes, vol. 69, no. 2, pp. 149-163, 1997.

[2] G. Grote, Management of uncertainty: theory and application in the design of systems and organizations. Dortrecht: Springer. H, 2009.

[3] Y. Kareev, "Seven (indeed, plus or minus two) and the selection of correlations," Psychological review, vol. 107, pp. 397-403, 2000.

[4] M. M. Crossan, H. W. Lane, and R. E. White, "An Organizational Learning Framework: From Intuition to Institution," The Academy of Management Review, vol. 24, no. 3 , pp. $522-537,1999$.

[5] G. P. Huber, "Organizational learning: The contributing processes and the literatures," Organization science, vol. 2, no. 1, pp. 88-115, 1991.

[6] D. Putz, J. Schilling, A Kluge, and C. Stangenberg. Measuring organizational learning from errors: Development and validation of an integrated model and questionnaire. Management Learning, 44 (5), 511-536, 2013.

[7] J. Schilling, and A. Kluge. Barriers to Organizational Learning: An Integration of Theory and Research. International Journal of Management Reviews, 11, 3, 337360, 2009.

[8] E. L. Bjork, R.A. Bjork, \& M.C. Anderson. Varieties of goal-directed forgetting. In J.M. Golding \& C.M. MacLeod, (Eds.), Intentional Forgetting: Interdisciplinary Approaches (S. 103-137). Mahwah, NJ: Lawrence Erlbaum, 1998.
[9] M. Lehman, M. and K. J. Malmberg. Overcoming the effects of intentional forgetting. Memory and Cognition, 39, 335-347, 2011.

[10] K.B. Payne, and E. Corrigan. Emotional constraints on intentional forgetting. Journal of Experimental Social Psychology, 43(5), 780-786, 2007.

[11] C.B. Harris, J. Sutton, and A.J. Barnier. Autobiographical forgetting, social forgetting, and situated forgetting. Forgetting in the context. In S. Della Sala (Ed.), Forgetting (S. 255- 284). Hove, East Sussex: Psychology Press, 2010.

[12] A. E. Akgün, G. S. Lynn, and J. C. Byrne, "Antecedents and Consequences of Unlearning in New Product Development Teams," Journal of Product Innovation Management, vol. 23, no. 1, pp. 73-88, Jan. 2006.

[13] M. C. Becker, "Organizational routines: a re- view of the literature," Industrial and corporate change, vol. 13, no. 4, pp. 643-678, 2004.

[14] A. J. Casey and F. Olivera, "Reflections on Organizational Memory and Forgetting," Journal of Management Inquiry, vol. 20, no. 3, pp. 305-310, Sep. 2011.

[15] P. M. de Holan and N. Phillips, "Remembrance of Things Past? The Dynamics of Organizational Forgetting," Management Science, vol. 50, no. 11, pp. 1603-1613, 2004.

[16] M. de Holan, N. Phillips, and T. B. Lawrence. Managing Organizational Forgetting. MIT Sloan Management Review, Winter 2004, 45-51, 2004. 